\title{
Clinical Characteristics and Incidence of Perianal Diseases in Patients With Ulcerative Colitis
}

\author{
Yong Sung Choi ${ }^{1}$, Do Sun Kim², Doo Han Lee ${ }^{2}$, Jae Bum Lee ${ }^{2}$, Eun Jung Lee ${ }^{2}$, Seong Dae Lee ${ }^{2}$, \\ Kee Ho Song 2 , Hyung Joong Jung ${ }^{2}$ \\ Departments of ${ }^{1}$ Gastroenterology and ${ }^{2}$ Surgery, Daehang Hospital, Seoul, Korea
}

Purpose: While perianal disease (PAD) is a characteristic of patients with Crohn disease, it has been overlooked in patients with ulcerative colitis (UC). Thus, our study aimed to analyze the incidence and the clinical features of PAD in patients with UC.

Methods: We reviewed the data on 944 patients with an initial diagnosis of UC from October 2003 to October 2015. PAD was categorized as hemorrhoids, anal fissures, abscesses, and fistulae after anoscopic examination by experienced proctologists. Data on patients' demographics, incidence and types of PAD, medications, surgical therapies, and clinical course were analyzed.

Results: The median follow-up period was 58 months (range, 12-142 months). Of the 944 UC patients, the cumulative incidence rates of PAD were $8.1 \%$ and $16.0 \%$ at 5 and 10 years, respectively. The incidence rates of bleeding hemorrhoids, anal fissures, abscesses, and fistulae at 10 years were $6.7 \%, 5.3 \%, 2.6 \%$, and $3.4 \%$, respectively. The cumulative incidence rates of perianal sepsis (abscess or fistula) were $2.2 \%$ and $4.5 \%$ at 5 and 10 years, respectively. In the multivariate analyses, male sex (risk ratio [RR], 4.6; 95\% confidence interval [CI], 1.7-12.5) and extensive disease (RR, 4.2; 95\% CI, 1.6-10.9) were significantly associated with the development of perianal sepsis.

Conclusion: Although the clinical course of PAD in patients with UC is not serious, in clinical practice, PAD is not rare in such patients. Therefore, careful examination and appropriate management for PAD is needed if the quality of life for patients with UC is to be improved.

Keywords: Perianal disease; Ulcerative colitis

\section{INTRODUCTION}

Perianal disease (PAD) is a common and clinically significant complication of Crohn disease (CD). The types of PAD can range

Received: April 2, 2017 - Accepted: June 8, 2017

Correspondence to: Yong Sung Choi, M.D.

Department of Gastroenterology, Daehang Hospital, 2151

Nambusunhwan-ro, Seocho-gu, Seoul 06699, Korea

Tel: +82-2-63888-114, Fax: +82-2-63888-115

E-mail:yschoi427@naver.com

ORCID code: https://orcid.org/0000-0003-0453-2322

This study was presented as poster at ECCO (European Cohn's and Colitis Organization) in Amsterdam, The Netherlands, 2016.

(C) 2018 The Korean Society of Coloproctology

This is an open-access article distributed under the terms of the Creative Commons Attribution NonCommercial License (http://creativecommons.org/licenses/by-nc/4.0) which permits unrestricted non-

commercial use, distribution, and reproduction in any medium, provided the original work is properly cited. from more favorable conditions such as hemorrhoids and fissures to more severe conditions such as abscesses and fistulae. The incidence ranges from approximately $13 \%$ to $27 \%$ in populationbased studies and from $35 \%$ to $45 \%$ in studies from tertiary referral centers [1-4]. The clinical course of CD with PAD seems to be unfavorable. If PAD is present at initial diagnosis, it is likely to progress more rapidly from inflammatory to stricturing or penetrating complications, which subsequently require more advanced medical therapies, such as the use of an immunomodulator or anti-tumor necrosis factor, and even surgical interventions $[5,6]$. Compared to Western countries, PAD at the time of diagnosis is encountered more frequently in Asian countries [7].

While PAD is a characteristic of patients with $\mathrm{CD}$, it tends to be rarely associated with patients with ulcerative colitis (UC) because the inflammation of UC is limited to the mucosa. Therefore, the clinical significance of PAD in patients with UC has been overlooked. However, PAD is not rare in such patients, and it can rep- 
resent a misleading problem in practice. For instance, bleeding hemorrhoids or fissures can be confused with a relapse of UC, which may lead to unnecessary anxiety for the patient and inappropriate escalation of current management; moreover, development of a fistula or an abscess in a patient with UC may raise concerns of misdiagnosed CD or indeterminate colitis [8]. Because the incidence and the clinical characteristics of PAD in patients with UC are unclear, our study aimed to estimate the incidence of $\mathrm{PAD}$ in such patients and to analyze the clinical features and the risk factors for the occurrence of perianal sepsis in those patients.

\section{METHODS}

We reviewed the data of 944 patients with an initial diagnosis of UC at Daehang Hospital, Seoul, from October 2003 to October 2015. Our hospital is a community-based hospital in Korea that specializes in coloproctology. We follow up on patients with UC every 2 or 3 months. Consultation for proctologic examination is not routine. If a patient with UC complains of any anal problem in the gastrointestinal clinic, we refer that patient to a proctologist on the same day. Therefore, when perianal symptoms develop in a patient with UC during the follow-up, PAD is diagnosed and categorized as a hemorrhoid, fissure, abscess and/or fistula after an anoscopic examination by an experienced proctologist. Data on patients for whom PAD occurred before diagnosis of UC were excluded. Patients' demographics, incidence and types of PAD, activity or extent of UC, family history, medication history (systemic corticosteroid or immunomodulators), surgical therapy, and clinical course of PAD were collected from October 2003 until October 2015 or loss of follow-up and were retrospectively analyzed. The study was approved by the Ethics Committee, Daehang Hospital (DH 16-0002). Because this was a retrospective study with minimal risk to patients, the Internal Review Board, Daehang Hospital, exempted it from obtaining informed consent from the patients whose records were included in the study.

UC was definitively diagnosed in the patients who met the following criteria: (1) typical history of diarrhea or blood and pus in the stool, or both, for longer than 4 weeks; (2) typical sigmoidoscopic or colonoscopic picture with loss of vascularity, friability, granularity, and/or ulcerations of colorectal mucosa in a continuous, circumferential pattern in the rectum; and (3) characteristic histopathologic signs of inflammation on biopsy, such as chronic inflammation or distortion of crypt architecture, inflammation of crypts, crypt abscesses, increased chronic inflammatory cells in the lamina propria, erosions, and/or ulcers. Proctitis was the diagnosis when the extent of the disease was limited to the rectum, left-sided colitis when the extent of the disease was limited to the proportion of the colon distal to the splenic flexure, and extensive disease when the disease extended proximal to the splenic flexure including pancolitis. Hemorrhoids were defined as an enlargement and distal displacement of the normal anal cushions, and in this study, symptomatic hemorrhoids were arbitrarily limited to bleeding hemorrhoids with or without anal discomfort. An anal fissure was defined as a tear or split in the distal anal canal. If pain was a prominent feature, an abscess needed to be excluded; this was often done by examination under anesthesia. An anal abscess was defined as an infected cavity filled with pus near the anus or the rectum. An anal fistula was defined as an abnormal communication between 2 epithelial surfaces, skin and anus or skin and rectum. A complex fistula was defined as a fistula tract with a high intersphincteric or high transsphincteric or extrasphincteric or suprasphincteric origin that might have multiple external openings and might be associated with a perianal abscess, with fistulas to adjacent organs, and with the presence of an anorectal stricture.

The cumulative incidence of PAD was calculated using the Kaplan-Meier method. In the univariate analyses, a log-rank test was used for comparisons between categorical variables, and an independent $\mathrm{t}$-test was used for comparisons between continuous variables. In multivariate analyses, a Cox regression hazard model was used. The risk ratio (RR) and the $95 \%$ confidence interval (CI) were calculated for predicting the relative risk of PAD development. $\mathrm{P}<0.05$ was considered statistically significant. All calculations were conducted using the SPSS ver. 15.0 (SPSS Inc., Chicago, IL, USA).

\section{RESULTS}

\section{Incidence of PAD in UC}

Of the 944 patients with UC (550 males and 394 females), the median age at the time of diagnosis was 40 years (range, 15-81 years), and the median follow-up period was 58 months (range, 12-142 months). The cumulative incidence rates of PAD were $8.1 \%$ and $16.0 \%$ at 5 and 10 years, respectively (Fig. 1). The incidence rates of bleeding hemorrhoids, anal fissures, abscesses and fistulae were $6.7 \%, 5.3 \%, 2.6 \%$, and $3.4 \%$ at 10 years, respectively.

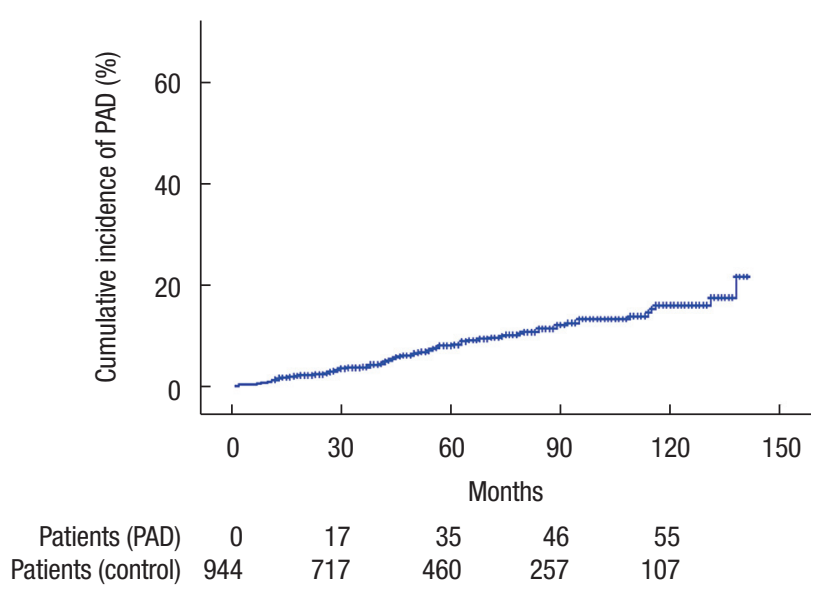

Fig. 1. Kaplan-Meier survival plot for the cumulative incidence of perianal disease $(\mathrm{PAD})$ in patients with ulcerative colitis $(\mathrm{n}=944)$. 
Table 1. Therapeutic outcomes of the perianal diseases that developed in patients with ulcerative colitis

\begin{tabular}{lcrcc}
\hline Perianal disease & $\begin{array}{c}\text { Medical } \\
\text { treatment }\end{array}$ & $\begin{array}{c}\text { Surgical } \\
\text { treatment }\end{array}$ & \multicolumn{2}{c}{ Postoperative Postoperative } \\
recurrence & complication \\
\hline Hemorrhoids & $16 / 38(42.1)$ & $22 / 38(57.9)$ & $0 / 18(0)$ & - \\
Anal fissure & $23 / 26(11.5)$ & $3 / 26(88.5)$ & $0 / 3(0)$ & - \\
Anal abscess & $3 / 11(27.3)$ & $8 / 11(72.7)$ & $1 / 8(12.5)$ & - \\
Anal fistula & $1 / 11(9.1)$ & $10 / 11(90.9)$ & $0 / 10(0)$ & - \\
\hline
\end{tabular}

Surgery for PAD was performed in 56 patients. The cumulative rates of surgery for PAD were $5.1 \%$ and $12.6 \%$ at 5 and 10 years, respectively.

Sixteen of the 38 patients (42.1\%) with hemorrhoids and 23 of the 26 patients (88.5\%) with an anal fissure improved conservatively without surgical intervention. For the three patients with an anal fissure that required surgery, a lateral sphincterotomy was used. Eight of the 11 patients $(72.7 \%)$ with a perianal abscess needed incision and drainage while the perianal abscess was resolved with conservative management for the other 3 patients. Ten of the 11 patients (90.9\%) with an anal fistula underwent surgical therapy; a simple fistulotomy was performed in all cases. No significant postoperative complications were encountered in any of the above-mentioned patients (Table 1).

\section{Risk factors of perianal sepsis (abscess or fistula)}

Among the 944 patients included in this study, perianal sepsis (abscess or fistula) was found 22 times among 21 of those patients. The cumulative incidence rates of perianal sepsis were 2.2\% and $4.5 \%$ at 5 and 10 years, respectively. Of these 21 patients, 18 (85.7\%) underwent surgical treatment, and among those $18 \mathrm{pa}-$ tients, 17 (94.4\%) showed no postoperative recurrence during the follow-up. Among the 11 patients with a perianal fistula, 8 (61.1\%) were found to have a simple type fistula and 3 (38.9\%) were found to have a complex type fistula ( 2 high intersphincteric and 1 high transsphincteric fistula). Of the 3 patients with a complex fistula, 2 had left-sided colitis, and 1 had extensive colitis.

In the univariate analyses for perianal sepsis, the patients with perianal sepsis were significantly associated with male sex and extensive disease $(\mathrm{P}<0.01)$. Patient age at diagnosis, extraintestinal complications, family history of inflammatory bowel disease (IBD), and use of an immunomodulator or a corticosteroid were not associated with perianal sepsis (Table 2, Fig. 2). In the multivariate analyses, male sex (RR, 4.6; 95\% CI, 1.7-12.5) and extensive disease (RR, 4.2; 95\% CI, 1.6-10.9) were independently associated with the development of perianal sepsis (Table 3).

\section{DISCUSSION}

The incidence of PAD in patients with UC varies greatly, ranging from $3.7 \%$ to $32 \%$, reflecting the inconsistent inclusion criteria for
Table 2. Clinical characteristics of patients having ulcerative colitis (UC) with or without perianal sepsis $(n=944)$

\begin{tabular}{|c|c|c|c|}
\hline Variable & $\begin{array}{c}\text { With } \\
\text { perianal sepsis } \\
(n=21)\end{array}$ & $\begin{array}{l}\text { Without } \\
\text { perianal sepsis } \\
(n=923)\end{array}$ & P-value* \\
\hline Age (yr) & 38 (15-65) & $40(15-81)$ & 0.04 \\
\hline Sex & & & $<0.01$ \\
\hline Male & $19(90.5)$ & $531(57.5)$ & \\
\hline Female & $2(9.5)$ & $392(42.5)$ & \\
\hline Extraintestinal complications & & & 0.11 \\
\hline Absent & 20 (95.2) & 906 (98.2) & \\
\hline Present & $1(4.8)$ & $17(1.8)$ & \\
\hline \multicolumn{4}{|l|}{ Family history of UC } \\
\hline Absent & $21(100)$ & 916 (99.2) & 0.60 \\
\hline Present & $0(0)$ & $7(0.8)$ & \\
\hline Extent of disease & & & $<0.01$ \\
\hline Proctitis & $9(42.9)$ & $517(56.1)$ & \\
\hline Left-sided colitis & $4(19.0)$ & $305(33.0)$ & \\
\hline Extensive colitis & $8(38.1)$ & $101(10.9)$ & \\
\hline Use of immunomodulators & & & 0.24 \\
\hline Absent & $18(85.7)$ & $868(94.0)$ & \\
\hline Present & $3(14.3)$ & $55(6.0)$ & \\
\hline Use of systemic corticosteroid & & & 0.33 \\
\hline Absent & $12(57.1)$ & 657 (71.2) & \\
\hline Present & $9(42.9)$ & $266(28.8)$ & \\
\hline
\end{tabular}

Values are presented as median (range) or number (\%).

*Log-rank.

PAD [9-13]. Moreover, the early studies from the 1960s and before may have included patients with misdiagnosed colonic $\mathrm{CD}$ or indeterminate colitis. The recent developments of endoscopic and imaging techniques and of more well-established diagnostic criteria for inflammatory bowel disease have made a more precise definition of UC patients with PAD possible. A recent study that examined patients with UC reported an incidence of PAD of $5 \%$, but hemorrhoids and fissures were excluded [14].

In our analysis, the cumulative incidence rate of PAD was not low, being approximately $16.0 \%$ at 10 years, which suggests that a sizeable proportion of the patients with UC actually suffer from anal problems. We initially hypothesized that the higher rate of anal problems in patients with UC compared to the general population was due to chronic and recurrent diarrhea. However, in the present study, proving whether the incidence rate of PAD in patients with UC was indeed significantly higher than it was in the general population was difficult because the study was not a population-based epidemiologic study. Very few epidemiologic studies designed to assess the prevalence of PAD have been published, and the prevalence rate varies widely with different study designs 

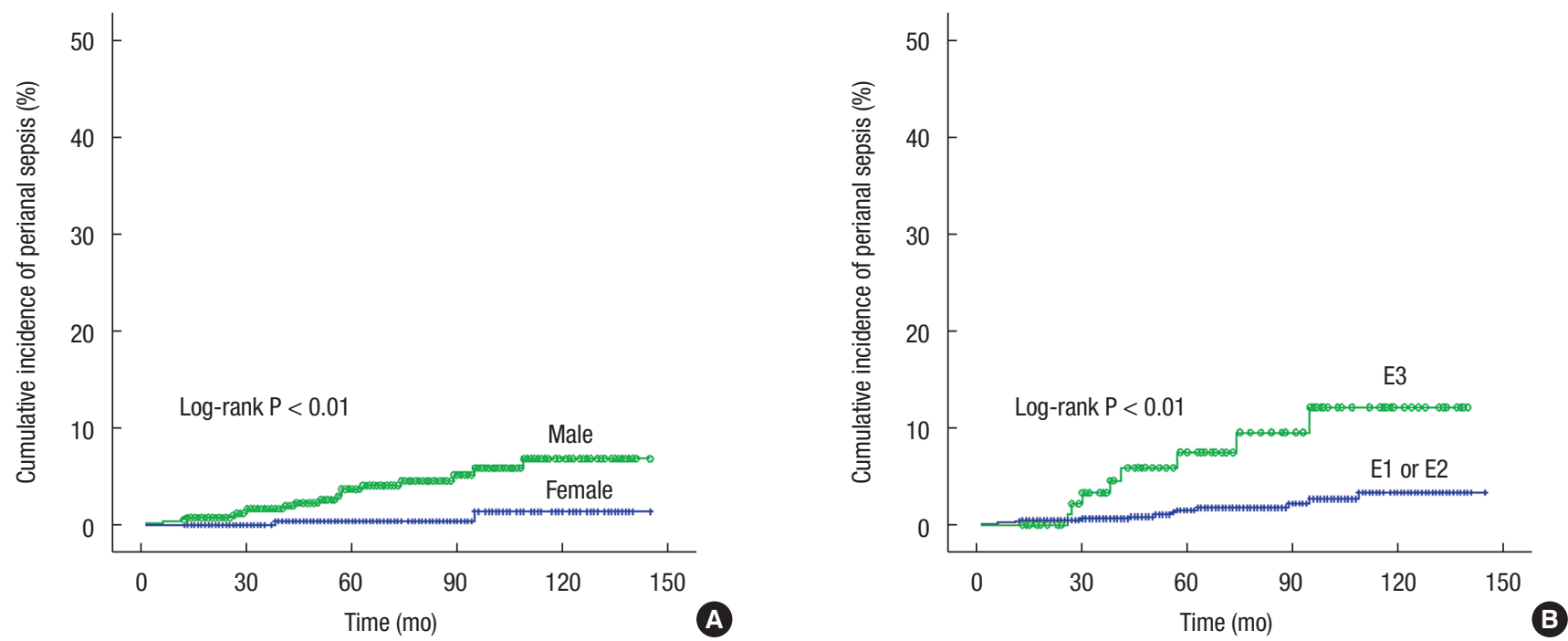

Fig. 2. Kaplan-Meier survival plots for the cumulative incidence of perianal sepsis in patients with ulcerative colitis according to sex (A) and extent of the disease (B).

Table 3. Results from the multivariate analyses of risk factors for perianal sepsis in patients with ulcerative colitis

\begin{tabular}{lcccc}
\hline Variable & SE & P-value & Risk ratio & $\begin{array}{c}95 \% \mathrm{Cl} \\
\text { for } \operatorname{EXP}(\mathrm{B})\end{array}$ \\
\hline Age $<40 \mathrm{yr}$ & 0.45 & 0.40 & 1.47 & $0.61-3.56$ \\
Male sex & 0.75 & $<0.01$ & 7.89 & $1.83-34.08$ \\
Corticosteroid & 0.53 & 0.82 & 0.89 & $0.31-2.53$ \\
Immunomodulator & 0.71 & 0.26 & 2.21 & $0.55-8.90$ \\
Extensive disease & 0.48 & $<0.01$ & 4.46 & $1.73-11.50$ \\
\hline
\end{tabular}

$\mathrm{SE}$, standard error; $\mathrm{Cl}$, confidence interval.

or patient inclusion criteria. For instance, an epidemiologic study from the United States reported a prevalence rate of hemorrhoids of $4.4 \%$ [15] while a population-based, self-reporting study from the United Kingdom reported a higher prevalence rate of $13 \%-$ $36 \%[16,17]$. In our data, the incidence rate of bleeding hemorrhoids requiring medical or surgical therapy was less than $10 \%$ at 10 years, although previous reports suggested that diarrhea was a risk factor for the development of hemorrhoids $[18,19]$. However, our data were not based on interviews, but on a diagnosis made by a coloproctologic surgeon based on the findings of an anoscopic examination. Also, the definition of symptomatic hemorrhoids was limited to advanced bleeding hemorrhoids requiring medical or surgical therapy. The high rate of surgery for hemorrhoids (57.9\%) suggests that advanced grades of hemorrhoids were included in our study.

In general, most hemorrhoids or fissures are clinically mild and only need conservative management. As a result, hemorrhoids and anal fissure in patients with UC have tended to be overlooked. However, their clinical significance differs from that of those not affected by UC. Hematochezia or anal pain can lead to misinterpretation of UC recurrence, which can cause unnecessary anxiety and degrade the quality of life. In addition, some inactive UC patients with anal problems may undergo colonoscopy or escalate the current medication. Thus, an appropriate management strategy for hemorrhoids and anal fissure is important for improving the quality of life in patients with UC. When hemorrhoids and anal fissure are confirmed, surgery is usually not preferred because of the possibility of sphincter injury; presently, no postoperative complications after surgery for hemorrhoids and anal fissure have occurred at our hospital.

Perianal abscess or fistula is a potentially disabling complication. The incidence rate in this study was $4.5 \%$ at 10 years. In particular, perianal fistulae are misleading and require more invasive surgical intervention. Generally in $\mathrm{CD}$, a patient with a simple perianal fistula without proctitis can be treated by using a fistulotomy or a fistulectomy, both of which have reported healing rates of up to $85 \%[20,21]$. On the other hand, if a risk of sphincter injury exists, incision and drainage, and usually placement of noncutting setons, are recommended for complex perianal fistulae. In our study, among 11 UC patients with a perianal fistula, 8 had a simple fistula and 3 had a complex fistula. The therapeutic plan for treating a perianal fistula in a patient with UC is not different from that for treating a patient with CD. In this study, a simple fistulectomy or a fistulotomy was performed in all cases; no postoperative complications were encountered.

In approximately one-third of the patients with UC with complex PAD, the initial diagnosis is changed, but this does not occur in any patient with simple PAD [14]. In this study, no change in diagnosis to $\mathrm{CD}$ was made for any of the patients with a complex fistula. The clinical courses of the patients with the complex fistulae were benign, and no postoperative complications occurred. 
Among the 18 patients who underwent surgery for perianal sepsis, recurrence occurred in only 1 patient. The patient was a 24-year-old female who had left-sided UC with a supralevator abscess. These results imply that, although rare, anal sepsis can occur even in patients with well-documented UC and that its clinical course is favorable.

In our multivariate analysis for the development of perianal sepsis, male sex and extensive disease were independent risk factors. Interestingly, a male predominance of perianal fistula $(6: 1)$ was similar to our data for a Crohn fistula $(3.8: 1)$ or a tuberculosis fistula $(6.3: 1)$ [22]. In fact, a male predominance of anal sepsis has also been noted in other epidemiologic studies targeting the general population (approximately 2 to $3: 1$ ). The cause of this male predominance is unclear. A male predominance is particularly marked in infancy, which suggests the existence of innate pathophysiologic differences between males and females. Although no evidence for a relationship between poor hygiene or smoking and the development of perianal sepsis was found, further investigation is needed. We can assume that the identification of extensive disease as a risk factor for perianal sepsis was secondarily related to the symptomatic disease activity, such as frequent bowel movement or diarrhea, and not to the direct pathophysiologic influence of those activities on the development of perianal sepsis. In fact, perianal sepsis in patients with UC is usually a sign of severe and persistent inflammation, with a high requirement for the use of corticosteroids $[13,14]$. Immunocompromised conditions have been related to the development of perianal sepsis [23-25]. However, in this study, the uses of immunomodulators and corticosteroids were not significantly related to the development of perianal sepsis. However, in this study, proving the existence of a relationship between anal sepsis and the use of immunosuppressant agents was difficult because the number of the patients using azathioprine was too small and the duration, dose and indication of the immunosuppressant agents were heterogeneous in our data. Among the eight azathioprine users who had anal sepsis, sepsis occurred before the administration of azathioprine.

To our knowledge, the present study is the only one to examine the cumulative incidence, clinical features and therapeutic result of PAD, including hemorrhoids and anal fissure, as well as abscess and fistula, in patients with UC. However, our study has some limitations. First, it is not a prospective cohort study. Therefore, the incidence of PAD was assessed only when the patients had symptomatic PAD and underwent anoscopic examination. However, the study was not done to evaluate the prevalence of PAD, but to predict the incidence of perianal complications in patients with UC during follow-up. Second, while smoking is one of the most important factors affecting the development of PAD, it was not investigated. The male predominance of perianal abscess or fistula may be related to smoking, but this association is unclear. Third, the number of the patients with perianal sepsis was relatively small, which hindered the analysis of its characteristics and risk factors. Nevertheless, although perianal sepsis is very rare in patients with UC, we suggest that research on the incidence of perianal sepsis would be informative because perianal sepsis can be potentially disabling and confusing, with misdiagnosed $\mathrm{CD}$ or indeterminate colitis in practice.

In conclusion, although the clinical course of PADs in patients with $\mathrm{UC}$ is not serious, in contrast to $\mathrm{CD}$, such diseases in patients with UC are not rare in practice and sometime requires perianal surgery. Careful examination and appropriate management of PAD in patients with UC is needed if the quality of life for such patients is to be improved.

\section{CONFLICT OF INTEREST}

No potential conflict of interest relevant to this article was reported.

\section{REFERENCES}

1. Schwartz DA, Loftus EV Jr, Tremaine WJ, Panaccione R, Harmsen WS, Zinsmeister AR, et al. The natural history of fistulizing Crohn's disease in Olmsted County, Minnesota. Gastroenterology 2002;122:875-80.

2. Fichera A, Michelassi F. Surgical treatment of Crohn's disease. J Gastrointest Surg 2007;11:791-803.

3. Tozer PJ, Whelan K, Phillips RK, Hart AL. Etiology of perianal Crohn's disease: role of genetic, microbiological, and immunological factors. Inflamm Bowel Dis 2009;15:1591-8.

4. Eglinton TW, Barclay ML, Gearry RB, Frizelle FA. The spectrum of perianal Crohn's disease in a population-based cohort. Dis Colon Rectum 2012;55:773-7.

5. Beaugerie L, Seksik P, Nion-Larmurier I, Gendre JP, Cosnes J. Predictors of Crohn's disease. Gastroenterology 2006;130:650-6.

6. Tarrant KM, Barclay ML, Frampton CM, Gearry RB. Perianal disease predicts changes in Crohn's disease phenotype-results of a population-based study of inflammatory bowel disease phenotype. Am J Gastroenterol 2008;103:3082-93.

7. Park SJ, Kim WH, Cheon JH. Clinical characteristics and treatment of inflammatory bowel disease: a comparison of Eastern and Western perspectives. World J Gastroenterol 2014;20:11525-37.

8. Hamzaoglu I, Hodin RA. Perianal problems in patients with ulcerative colitis. Inflamm Bowel Dis 2005;11:856-9.

9. Jackman RJ. Management of anorectal complications of chronic ulcerative colitis. AMA Arch Intern Med 1954;94:420-4.

10. Bockus HL, Roth JL, Buchman E, Kalser M, Staub WR, Finkelstein A, et al. Life history of nonspecific ulcerative colitis: relation of prognosis to anatomical and clinical varieties. Gastroenterologia 1956;86:549-81.

11. Fuzy PJ Jr. Surgical management of anorectal complications of chronic ulcerative colitis. South Med J 1961;54:785-7.

12. Edwards FC, Truelove SC. The course and prognosis of ulcerative colitis. III. Complications. Gut 1964;5:1-22. 
13. de Dombal FT, Watts JM, Watkinson G, Goligher JC. Incidence and management of anorectal abscess, fistula and fissure, in patients with ulcerative colitis. Dis Colon Rectum 1966;9:201-6.

14. Zabana Y, Van Domselaar M, Garcia-Planella E, Mañosa M, San Román AL, Gordillo J, et al. Perianal disease in patients with ulcerative colitis: a case-control study. J Crohns Colitis 2011;5:33841.

15. Johanson JF, Sonnenberg A. The prevalence of hemorrhoids and chronic constipation. An epidemiologic study. Gastroenterology 1990;98:380-6.

16. Gazet JC, Redding W, Rickett JW. The prevalence of haemorrhoids. A preliminary survey. Proc R Soc Med 1970;63 Suppl:78-80.

17. Loder PB, Kamm MA, Nicholls RJ, Phillips RK. Haemorrhoids: pathology, pathophysiology and aetiology. Br J Surg 1994;81:94654.

18. Johanson JF, Sonnenberg A. Constipation is not a risk factor for hemorrhoids: a case-control study of potential etiological agents. Am J Gastroenterol 1994;89:1981-6.

19. Johanson JF. Association of hemorrhoidal disease with diarrheal disorders: potential pathogenic relationship? Dis Colon Rectum 1997;40:215-9.

20. Williams JG, Farrands PA, Williams AB, Taylor BA, Lunniss PJ, Sagar PM, et al. The treatment of anal fistula: ACPGBI position statement. Colorectal Dis 2007;9 Suppl 4:18-50.

21. Sangwan YP, Schoetz DJ Jr, Murray JJ, Roberts PL, Coller JA. Perianal Crohn's disease. Results of local surgical treatment. Dis Colon Rectum 1996;39:529-35.

22. Choi YS, Kim DS, Lee JB, Kim JK, Jung HJ, Lee SD, et al. Clinical features of tuberculous versus Crohn's anal fistulas, in Korea. J Crohns Colitis 2015;9:1132-7.

23. Büyükaşik Y, Ozcebe OI, Sayinalp N, Haznedaroğlu IC, Altundağ OO, Ozdemir O, et al. Perianal infections in patients with leukemia: importance of the course of neutrophil count. Dis Colon Rectum 1998;41:81-5.

24. Muñoz-Villasmil J, Sands L, Hellinger M. Management of perianal sepsis in immunosuppressed patients. Am Surg 2001;67:484-6.

25. Rayner CK, McCormack G, Emmanuel AV, Kamm MA. Longterm results of low-dose intravenous ciclosporin for acute severe ulcerative colitis. Aliment Pharmacol Ther 2003;18:303-8. 